\title{
Study on the relationship between respiratory scores and hyponatremia in children with bronchiolitis
}

\author{
Yelda Turkmenoglu', Alper Kacar², Diğdem Bezen³, Haticenur Kırar', \\ Ebru Mısırlı Özdemir ${ }^{1}$, Ahmet İrdem ${ }^{5}$, Mey Talip Petmezci ${ }^{6}$, Hasan Dursun ${ }^{7}$ \\ ${ }^{1}$ Pediatrician, ${ }^{2}$ Pediatrician (Pediatric Emergency), ${ }^{3}$ Pediatrician (Pediatric Endocrinology), ${ }^{5}$ Assistant Professor \\ (Pediatric Cardiology), ${ }^{6}$ Pediatrician (Pediatric Intensive Care Unit), ${ }^{7}$ Assistant Professor (Pediatric Nephrology), \\ Department of Pediatrics, University of Health Science Okmeydani Training and Research Hospital, Istanbul, Turkey, \\ ${ }^{4}$ Pediatrician, Department of Pediatrics, Medipol University Mega Hospital, Istanbul. Turkey
}

Background: Tal et al. severity score (TSS) and Modified Wood's Clinical Asthma Score (M-WCAS) are used to evaluate the severity of the disease in children with bronchiolitis. It has recently been suggested that there is a relationship between bronchiolitis severity and hyponatremia. Aims and Objective: This study aimed to evaluate the relationship between both of scores and hyponatremia in children with bronchiolitis. Materials and Methods: This prospective observational study included 172 patients (age range: 1-24 months) admitted to the hospital with bronchiolitis diagnosis. Demographic and clinical features of patients were recorded, and the TSS and the M-WCAS were calculated. These values and their components were compared with serum sodium $(\mathrm{Na})$ results obtained at hospital admission. Results: Of the 172 patients, $114(66.3 \%)$ were male, and the mean age was $5.5 \pm 4.6$ months. The mean TSS and M-WCAS of the patients were $6.73 \pm 1.9$, and $3.34 \pm 1.4$, respectively. Hyponatremia $(\mathrm{Na}<135 \mathrm{mEq} / \mathrm{L})$ was detected in $30(17.4 \%)$ patients. When the TSS and M-WCAS of patients with and without hyponatremia were compared, there was no statistically significant difference $(p=0.517 ; p=0.662$, respectively); however, there was a significant relationship between hyponatremia and low oxygen saturation levels $(p=0.026)$. Conclusion: No relationship was found between hyponatremia and TSS \& M-WCAS. However, the relationship between hyponatremia and hipoxia suggests that hyponatremia is likely to increase with the severity of the disease.

Key words: Bronchiolitis; clinical score; hyponatremia; infant

\section{INTRODUCTION}

Respiratory system infections are the most frequently encountered diseases in children worldwide the globe. In particular, bronchiolitis, often occurs during the first two years of life, and it is the leading cause of respiratory illness hospitalizations among this age group. The most common factors of this disease, that peak in winter, are respiratory viruses, including respiratory syncytial virus (RSV), rhinovirus, influenza virus, human parainfluenza virus (HPIV), adenoviruses, and human metapneumovirus. ${ }^{1,2}$ Signs and symptoms start with rhinitis and cough often progress from mild to severe, ultimately reaching the lower respiratory tract. Edema characterized by inflammation of the small airways along with necrosis and increased mucus accumulation in epithelial cells, causes a clinical picture involving tachypnea, wheezing, rales and/or use of accessory respiratory muscles. ${ }^{3}$ Although the disease usually follows a moderate course, it requires hospitalization in infants with concomitant conditions such as congenital lung disease, congenital heart defect, neuromuscular disorders, premature birth, and immune deficiency. ${ }^{1,2,4}$ 
Respiratory function tests designed to measure the degree of airway obstruction have limited use in infants. For this reason, various clinical scoring systems and tools have been developed to determine disease severity based on the respiratory rate (number of breaths taken per minute), cyanosis, cerebral function, wheezing, crepitan rales, intensity of accessory respiratory muscle use, and oxygen saturation. Higher scores on such assessment tools are claimed to indicate an increase in the severity of bronchiolitis. In this context, the Tal et al. severity score (TSS) and Modified Woods Clinical Asthma Score (M-WCAS) are simple and practical clinical tools that may offer validated scores to predict the severity of the disease..$^{5-8}$

Some infants with acute bronchiolitis who have no concomitant disease have also been observed to show severe symptoms of the disease. Hyponatremia is also frequently observed in patients with severe respiratory distress. It has been suggested that low serum sodium $(\mathrm{Na})$ levels $(<135 \mathrm{mEq} / \mathrm{L})$ among infants with bronchiolitis could play a role in determining the severity of the disease, and the presence of hyponatremia may complicate the prognosis, especially in those receiving critical care in pediatric intensive care units (PICU), ${ }^{9,10}$ Although hyponatremia is also observed in non-PICU patients with bronchiolitis, its relationship with the severity of the disease remains unknown. ${ }^{11,12}$ Therefore, this study therefore aims to determine the severity of acute bronchiolitis in infants using two different assessment tools, named TSS and M-WCAS, and compare the severity scores with serum sodium levels.

\section{MATERIALS AND METHODS}

This prospective observational study was carried out at the Okmeydani Research and Training Hospital, University of Health Sciences, between 1 November 2018 and 1 April 2019. Before the initiation of any research protocol, written informed consent was obtained from each patient's parent(s) once they had been given a detailed explanation of the aims and scope of the study. The study was conducted following the principles of the Declaration of Helsinki by the World Medical Association. In addition, written approval for the study was obtained from local ethics committee (998/09.10.2018). The diagnosis of bronchiolitis was established in the presence of cough, wheezing, and rales, characterized by respiratory distress accompanied by symptoms of acute coryza (upper respiratory tract infection), tachypnea, and use of accessory respiratory muscles., ${ }^{1,2}$

The study initially included 205 patients aged between 1 and 24 months; however, 33 patients were excluded from the study for various reasons, including lack of blood gas test results (14 patients), repeated hospitalizations (seven patients), presence of serious unstable cardiac disease (three patients), bacterial infections (five patients), and diarrhea (four patients). Thus, the final sample was comprised of 172 patients.

\section{Inclusion criteria}

Patients aged 1 - 24 months old and born after a full-term pregnancy (gestational week $\geq 37$ ) with normal birth weight and hospitalized for bronchiolitis were included in the study.

\section{Exclusion criteria}

Patients younger than 1 month old and older than 24 months old, and those with accompanying conditions (congenital heart disease, neuromuscular disorder, congenital malformations), those with diarrhea, those and a history of hospitalization due to bronchiolitis, born prematurely (at gestational week <37), and low birth weight were excluded from the study.

As our country has been regularly performing newborn screening for cystic fibrosis over the past few years, patients with negative screening results were considered not to have cystic fibrosis. For the calculation of TSS and M-WCAS, two physicians evaluated each patient's respiratory rate, presence of cyanosis, degree of wheezing and inspiratory sounds during auscultation, use of accessory respiratory muscles and levels of oxygen saturation, and cerebral function. Then, the physicians, by averaging these values, calculated and recorded TSS and M-WCAS for each patient. In addition, a series of laboratory tests, including complete blood count, C-reactive protein (CRP), serum $\mathrm{Na}$, and venous blood gases were performed within two hours of admission. A power of hydrogen $(\mathrm{pH})>7.3$ and partial pressure of carbon dioxide $(\mathrm{pCO} 2)>50 \mathrm{mmHg}$ in venous blood gas analyses were accepted as respiratory distress. ${ }^{13}$

A sodium concentration in the serum higher than $135 \mathrm{mmol} / \mathrm{L}(\mathrm{Na} \geq 135 \mathrm{mmol} / \mathrm{L})$ was considered normal, while values less than $135 \mathrm{mmol} / \mathrm{L}(\mathrm{Na}$ $<135 \mathrm{mmol} / \mathrm{L}$ ) were considered hyponatremia, with levels from 134 to $130 \mathrm{mmol} / \mathrm{L}$ categorized as mild hyponatremia, $129-120 \mathrm{mmol} / \mathrm{L}$ moderate and $<120 \mathrm{mmol} / \mathrm{L}$ severe. ${ }^{14}$ Chest radiographs were taken from all patients, and those showing signs of infiltration and congenital malformations on chest radiography as well as patients presenting findings compatible with immune deficiency and those with positive bacterial blood cultures were excluded from the study. Echocardiography was performed in patients with tachypnea and abnormal heart murmur, and those diagnosed with unstable heart disease were also excluded. For viral etiology, antibody identification was conducted in samples from 60 patients. Laboratory results were individually compared with TSS and M-WCAS, and then both scores were compared to each other. 


\section{Statistical analysis}

Statistical analysis was performed using the statistical package IBM SPSS Statistics 22 (IBM SPSS, Turkey). For each continuous variable, the normality of the data distribution was checked using the Kolmogorov-Smirnov test. All numerical data are expressed as median values (minimum-maximum) or as proportions. Groups with normally distributed data were compared using a one-way ANOVA test; groups with abnormally distributed data were compared using the Kruskal-Wallis test. Dun's test was used to determine the causes of abnormality, and these two groups were compared using the Mann-Whitney U test. The categorical variables between the groups were analyzed using the chi-squared test or the Fisher-Freeman test. The correlations between normally distributed variables were tested using the Pearson correlation test. A p-value of less than 0.05 was considered statistically significant.

\section{RESULTS}

The mean age of the 172 patients was $5.5 \pm 4.6(1-24)$ months, and $114(66.3 \%)$ of them were male. The most common complaints of patients were cough with an incidence rate of $95.9 \%$, runny nose $(66.3 \%)$, loss of appetite and difficulty in feeding $(64.5 \%)$, grunt $(59.3 \%)$, fever $(>37.5 \mathrm{C})(59.3 \%)$, and difficulty in breathing $(51.2 \%)$. Analysis of the samples taken from 60 patients for viral etiology revealed exposure to RSV in 26 patients (43.3\%), influenza in $18(30.0 \%)$, rhinovirus in $11(18.3 \%)$, adenovirus in $4(6.7 \%)$, and metapneumovirus in 1 patient $(1.66 \%)$. Time from onset of symptoms to hospital admission was $2.5 \pm 2.6$ days on average. The total scores of TSS changed from 3 to 11 (mean $6.73 \pm 1.94$, median 7 ) and M-WCAS changed from 1 to 8 (mean, $3.34 \pm 1.38$; median, 3) (Table 1).

The M-WCAS scores of patients were mild in 91 (52.9\%), moderate in $73(42.5 \%)$, and severe in eight (4.6\%) patients.

In addition, the complete blood count, $\mathrm{CRP}, \mathrm{Na}$, and blood gas results of the patients were evaluated, as shown in Table 1.

Hyponatremia was detected in $30(17.4 \%)$ patients, of which 21 were males. When patients were divided into age groups, hyponatremia was seen in nine patients 1-3 months old, 13 patients 3-6 months old, five patients 7-12 months old, and three patients 13-24 months old. Among patients with hyponatremia, the M-WCAS was categorized as low in 13 patients, moderate in 15 patients, and high in two patients. In patients with hyponatremia, 28 (16.3\%) had mild hyponatremia, and two $(1.2 \%)$ had moderate hyponatremia.
The comparison of the mean TSS and M-WCAS in patients with or without hyponatremia showed no significant difference between these groups $(p=0.517, p=0.662$, respectively) (Table 2 ).

In addition, the numeric components of TSS and M-WCAS were analyzed. There was no statistically significant difference between patients with and without hyponatremia in terms of respiratory rate groups $(p=0.997)$, but there was a significant difference between hyponatremia and oxygen saturation levels $(p=0.026)$ (Table 3$)$.

Patients received intravenous fluid electrolyte therapy. The levels of $\mathrm{Na}$ were all resolved after fluid treatment, and their serum sodium values were normal before discharge.

\section{DISCUSSION}

It has been reported that hyponatremia occurs in 16$22 \%$ of bronchiolitis patients treated in the PICU due to respiratory distress, playing a significant role in mortality. ${ }^{9,10}$ The impact of higher respiratory scores on serum sodium levels remains unknown. There are no studies in the

\begin{tabular}{|c|c|c|}
\hline Parameters & \multicolumn{2}{|c|}{ Patients $(n=172)$} \\
\hline $\begin{array}{l}\text { Gender } \\
\text { Girl/boy }\end{array}$ & $\begin{array}{c}n \\
58 / 114\end{array}$ & $\begin{array}{c}\% \\
33.7 / 66.3 \\
\end{array}$ \\
\hline Min-Max & \multicolumn{2}{|c|}{ Mean $\pm S D$} \\
\hline Age (month) & $5,5 \pm 4,6$ & $4(1-24)$ \\
\hline TSS & $6,7 \pm 1,9$ & $7(3-11)$ \\
\hline M-WCAS & $3,3 \pm 1,4$ & $3(1-8)$ \\
\hline WBC $\left(10^{3} / \mathrm{mm}^{3}\right)$ & $4720-18410$ & $11042,34 \pm 3314,82$ \\
\hline $\operatorname{ANC}\left(10^{3} / \mathrm{mm}^{3}\right)$ & $700-9460$ & $4184,42 \pm 1951,02$ \\
\hline $\mathrm{Hb}(\mathrm{g} / \mathrm{dL})$ & $8,1-15,1$ & $10,94 \pm 1,13$ \\
\hline $\begin{array}{l}\text { Platelet count } \\
\left(10^{3} / \mathrm{mm}^{3}\right)\end{array}$ & $159-841$ & $393,77 \pm 119,82$ \\
\hline CRP (g/L) (median) & $0-76$ & $12,35 \pm 15,56(6,7)$ \\
\hline $\mathrm{Na}(\mathrm{mmol} / \mathrm{L})$ & $127-143$ & $136,32 \pm 2,33$ \\
\hline $\mathrm{pH}$ & $7,19-7,7$ & $7,36 \pm 0,05$ \\
\hline $\begin{array}{l}\mathrm{pCO}_{2}(\mathrm{mmHg}) \\
\mathrm{HCO}_{3}(\mathrm{mmol}\end{array}$ & $26,7-67,6$ & $41,15 \pm 7,23$ \\
\hline
\end{tabular}

ANC: Absolute neutrophil count; CRP: C-reactive protein; Max: Maximum; Med: Median; Min: minimum; M-WCAS: Modified Woods Clinical Asthma Score; SD: Standard deviation; WBC: White blood cell; $\mathrm{Hb}$ : hemoglobin; $\mathrm{PH}$ : Power of Hydrogen; $\mathrm{CO}_{2}$ : Partial pressure of carbon dioxide; $\mathrm{HCO}_{3}$ : Bicarbonate

\begin{tabular}{lcc} 
Table 2: Comparison of the mean TSS and \\
M-WCAS and hyponatremia \\
\multicolumn{4}{l}{ TSS } & M-WCAS \\
\hline Hyponatremia & Mean $\pm S D$ (median) & Mean $\pm S D$ (median) \\
\hline None & $6.67 \pm 1.90(7)$ & $3.32 \pm 1.38(3)$ \\
Positive & $7.0 \pm 2.12(7)$ & $3.43 \pm 1.37(3,3)$ \\
p & 0.517 & 0.662 \\
\hline
\end{tabular}

Mann Whitney U Test * $p<0.05$ SD: Standard deviation; TSS: Tal et al. severity score; M-WCAS: Modified Woods Clinical Asthma Score 


\section{Table 3: Numeric components of TSS and M-WCAS based on the hyponatremia distribution}

\begin{tabular}{|c|c|c|c|c|}
\hline \multirow[t]{2}{*}{ Parameter } & \multicolumn{3}{|c|}{ Hyponatremia } & \multirow[b]{2}{*}{$\mathbf{p}$} \\
\hline & & None & Positive & \\
\hline & & n (\%) & n (\%) & \\
\hline \multirow[t]{3}{*}{ Respiratory Rate (rate/minute) } & $30-45 /$ minute & $20(14.1)$ & $4(13.8)$ & 0.997 \\
\hline & $46-60 /$ minute & $74(52.1)$ & $15(51,7$ & \\
\hline & $>60 /$ minute & $48(33.8)$ & $10(34.5)$ & \\
\hline \multirow{3}{*}{ Saturation $\mathrm{O}_{2}$} & >\%95 (air of room) & $60(42.3)$ & $12(40)$ & ${ }^{+} 0.026 *$ \\
\hline & $>\% 90$ with $\mathrm{FiO} 2>21 \%$ & $18(12.7)$ & $9(30)$ & \\
\hline & $<\% 90$ with $\mathrm{FiO} 2>21 \%$ & $3(2.1)$ & $2(6.7)$ & \\
\hline
\end{tabular}

literature that investigate the relationship between TSS or M-WCAS and hyponatremia. In our study, hyponatremia was detected in $17.4 \%$ of bronchiolitis patients at the time of admission, but no relationship was found between hyponatremia and TSS score or M-WCAS to predict disease severity. Our sample appears to have included mild to moderate cases of bronchiolitis, and only eight patients had high scores for M-WCAS that indicated severe disease, two of whom had hyponatremia.

A study showed that in infants with bronchiolitis, M-WCAS $\geq 7$, and oxygen saturation $<75 \%$, there is an increased necessity for intubation. ${ }^{8}$ However; they did not compare these values with their hyponatremia. When we compared the components of the M-WCAS with hyponatremia, we found relationship between the groups low oxygen saturation and hyponatremia, which suggests that hypoxia, may affect the development of hyponatremia.

It has been pointed out that one of the causes of hyponatremia in bronchiolitis is the administration of large volumes of hypotonic solution. ${ }^{14,15}$ Another view argues that it may be the limitation of oral intake due to increased respiratory load and an increase in sweating and loss of sodium. ${ }^{16}$ Tachypnea has also been investigated as a possible cause of hyponatremia in children with pnemonia. ${ }^{17}$ We found no relationship between the groups of respiratory rates and hyponatremia in our study. In an experimental study, influenza, parainfluenza, and RSV have been shown to damage the apical face of the epithelium in the lung, disrupting sodium transport. ${ }^{18}$ However, it is not known whether this local effect systemically causes hyponatremia. Elevated antidiuretic hormone (ADH) secretion is associated with hyponatremia, particularly in bronchiolitis caused by RSV. ${ }^{15,19}$ ADH levels have been reported to increase in different clinical conditions, such as fever, hypovolemia, and respiratory infections. ${ }^{20}$ Extracellular fluid volume contraction, also known as volume depletion or reduction in effective arterial blood volume, is thought to cause hyponatremia by affecting the renin-angiotensin system..$^{21,22}$ In our patients, hyponatremia was detected by the tests performed before the commencement of fluid treatment, and oral intake was decreased in a significant portion of our patients. Daniemend et al., ${ }^{21}$ suggested that a decrease in oral intake had no effect on hyponatremia, whereas increased ADH, $\mathrm{N}$-terminal pro-atrial, and $\mathrm{N}$-terminal pro-brain natriuretic peptide levels were associated with the development of hyponatremia in patients with bronchiolitis. A study by Hausman-Kedem et al., ${ }^{22}$ investigating brain natriuretic peptide (BNP) levels in 49 children with pneumonia, found no relationship between BNP levels and oxygen saturation and hyponatremia. However, they defined hyponatremia as $\mathrm{Na}<133 \mathrm{mEq} / \mathrm{L}$. In an experimental study, atrial natriuretic peptide and B-type natriuretic peptide levels have been reported to be elevated in hypoxia. ${ }^{23}$ This suggests that patients with respiratory distress may develop hyponatremia with elevated levels of these peptides because of hypoxia. The idea of hyponatremia caused by hypoxia supports our study.

Hyponatremia also appears to accompany pulmonary exacerbations of cystic fibrosis, pneumonia, bronchiolitis, bronchitis, and upper respiratory system infections. ${ }^{11,24}$ Hyponatremia is particularly common and severe in RSV bronchiolitis, causing neurological symptoms such as convulsions. ${ }^{16,25}$ A study by Park et al., ${ }^{11}$ that included 3938 children with lower and upper respiratory system infections, 724 of which had bronchiolitis, reported that the frequency of hyponatremia was $9.7 \%$, and it was observed especially in male patients and older children and no severe hyponatremia and convulsion occurred. All patients were discharged after their condition improved. Most of our patients were male, under two years of age, and severe hyponatremia and convulsions were not observed.

In a study of 91 infants aged 6 weeks on average receiving critical care in the PICU for RSV infection, serum sodium values were less than $136 \mathrm{mEq} / \mathrm{L}$ in $33 \%$ of patients and $<130 \mathrm{mEg} / \mathrm{L}$ in $11 \%$ of patients. ${ }^{16}$ Different studies have detected hyponatremia in $9.7-57 \%$ of infants with bronchiolitis admitted to the pediatric wards. ${ }^{11,12}$ Our 
study generally included mild and moderate cases of bronchiolitis in children born at normal gestational age with no accompanying disease, age range from 1-24 months. The majority of patients had mild hyponatremia, and only two patients $(1.2 \%)$ had serum sodium levels less than $130 \mathrm{mmol} / \mathrm{L}$, while no severe hyponatremia and convulsion was observed. Comparable results were achieved in all age groups in our study. In mild or moderate cases of bronchiolitis where hyponatremia persists, physicians should consider the possibility of other diseases, such as cystic fibrosis.

This study has some limitations. The study was conducted with a relatively limited number of patients, and the number of cases with severe bronchiolitis was low. There was no data regarding the serum sodium levels of patients before hospital admission. Not all bronchiolitis cases in our study had the same causative agent; further studies, including cases with the same etiologic agent, may yield different results.

\section{CONCLUSION}

In conclusion, most of our patients with acute bronchiolitis had mild to moderate hyponatremia. There was no significant correlation between respiratory scores (TSS and M-WCAS) and hyponatremia, but there is a relationship between low oxygen saturation and hyponatremia, suggesting that hypoxia may play a role in the development of hyponatremia. Extensive research with larger samples is needed to better evaluate the relationship between hyponatremia and hypoxia in children with bronchiolitis.

\section{ACKNOWLEDGEMENT}

We thanks to Ebru Osmanoglu for statistically support.

\section{REFERENCES}

1. Ralston S, Lieberthal, Meissner H, Alverson B, Baley JE, Gadomski AM, et al. American Academy of Pediatrics. Clinical practice guideline: the diagnosis, management, and prevention of bronchiolitis. Pediatrics. 2014; 134: e1474-e1502.

https://doi.org/10.1542/peds.2014-2742

2. Smyth RL and Openshaw PJ. Bronchiolitis. Lancet. 2006; 368: 312-322.

https://doi.org/10.1016/S0140-6736(06)69077-6

3. Flores-González JC, Mayordomo-Colunga J, Jordan I, MirasVeiga AM, Montero-Valladares C, Olmedilla-Jodar M, et al. Prospective Multicentre Study on the Epidemiology and Current Therapeutic Management of Severe Bronchiolitis in Spain. BioMed Res Int. 2017; 2017: 2565397.

https://doi.org/10.1155/2017/2565397

4. Ricart S, Marcos MA, Sarda M, Anton A, Muñoz-Almagro C, Pumarola $\mathrm{T}$, et al. Clinical risk factors are more relevant than respiratory viruses in predicting bronchiolitis severity. Pediatr Pulmonol. 2013; 48: 456-463.

https://doi.org/10.1002/ppul.22633

5. Tal A, Bavilski C, Yohai D, Bearman JE, Gorodischer R and Moses SW. Dexamethasone and salbutamol in the treatment of acute wheezing in infants. Pediatrics. 1983; 71:13-18.

6. Wood DW, Downes JJ and Lecks HI. A clinical scoring system for the diagnosis of respiratory failure. Am J Dis Child. 1972; 123: 227-228.

https://doi.org/10.1001/archpedi.1972.02110090097011

7. Duarte-Dorado DM, Madero-Orostegui DS, RodriguezMartinez CA and Nino G. Validation of a scale to assess the severity of bronchiolitis in a population of hospitalized infants. J Asthma. 2013;50:1056-1061.

https://doi.org/10.3109/02770903.2013.834504

8. Colombo J, Gattoni C, Carobbio A, Nacoti M, Pellicioli I, Vedovati S, et al. Risk factors for intubation in severe bronchiolitis: a useful tool to decide on an early intensive respiratory support. Minerva Pediatr. 2020; 2.

9. Hasegawa K, Stevenson MD, Mansbach JM, Schroeder AR, Sullivan AF, Espinola JA, et al. Association between hyponatremia and higher bronchiolitis severity among children in the ICU with bronchiolitis. Hosp Pediatr. 2015;5:385-389. https://doi.org/10.1542/hpeds.2015-0022

10. Luu R, DeWitt PE, Reiter PD, Dobyns EL and Kaufman J. Hyponatremia in children with bronchiolitis admitted to the pediatric intensive care unit is associated with worse outcomes. J Pediatr. 2013;163:1652- 6e1. https://doi.org/10.1016/j.jpeds.2013.06.041

11. Park SW, Shin SM, Jeong M, Cho D, Lee KH, Eisenhut M, et al. Hyponatremia in children with respiratory infections: a crosssectional analysis of a cohort of 3938 patients. Sci Rep. 2018;8(1):16494.

https://doi.org/10.1038/s41598-018-34703-1

12. Milani GP, Rocchi A, Teatini T, Bianchetti MG, Amelio G, Mirra N, et al. Hyponatremia in infants with new onset moderate-severe bronchiolitis: A cross-sectional study. Respir Med.2017;133: 48-50.

https://doi.org/10.1016/j.rmed.2017.10.028

13. Kelly GS, Simon HK and Sturm JJ. High-flow nasal cannula use in children with respiratory distress in the emergency department: predicting the need for subsequent intubation. Pediatr Emerg Care. 2013;29:888-892. https://doi.org/10.1097/PEC.0b013e31829e7f2f

14. Shein SL, Slain K, Schlurmann NM, Speicher R and Rotta AT. Hyponatremia and hypotonic intravenous fluids are associated with unfavorable outcomes of bronchiolitis admissions. Hosp Pediatr. 2017;7:263-270.

https://doi.org/10.1542/hpeds.2016-0205

15. Hanna S, Tibby SM, Durward A and Murdoch IA. Incidence of hyponatraemia and hyponatraemic seizures in severe respiratory syncytial virus bronchiolitis. Acta Paediatr. 2003;92:430-434.

16. Lavagno C, Milani GP, Uestuener P, Simonetti GD, Casaulta C, Bianchetti MG, et al. Hyponatremia in children with acute respiratory infections: A reappraisal. Pediatr Pulmonol. 2017; 52: 962-967.

https://doi.org/10.1002/ppul.23671

17. Sakellaropoulou A, Hatzistilianou M, Eboriadou $M$ and Athanasiadou-Piperopoulou F. Hyponatraemia in cases of children with pneumonia. Arch Med Sci. 2010 (30); 6: 578-583. https://doi.org/10.5114/aoms.2010.14471

18. Kunzelmann K, Sun J, Meanger J, King NJ and Cook DI. 
Inhibition of Airway Na Transport by Respiratory Syncytial Virus. J Virol. 2007: 3714-3720. https://doi.org/10.1128/JVI.02621-06

19. Gozal D, Colin AA, Jaffe M and Hochberg Z. Water, electrolyte, and endocrine homeostasis in infants with bronchiolitis. Pediatr Res. 1990;27:204-209.

https://doi.org/10.1203/00006450-199002000-00023

20. Edwards KD and Tighe MP. How to use N-terminal pro-brain natriuretic peptide (NT-proBNP) in assessing disease severity in bronchiolitis. Arch Dis Child Educ Pract Ed 2020; 105 :282-288. https://doi.org/10.1136/archdischild-2019-316896

21. Daneshmand KA, Zaritskyy AL, Lamb MA, LeVine AM, Theriaque DW and Sanders RC. Plasma concentration of $\mathrm{N}$-terminal pro-atrial and $\mathrm{N}$-terminal pro-brain natriuretic peptides and fluid balance in children with bronchiolitis. J Pediatr Intensive Care. 2012;1:143-151.

22. Hausman-Kedem M, Reif S, Danino D, Limor R, Grinspan ZM, Yerushalmi-Feler $A$, et al. Mechanism of Hyponatremia in
Community-Acquired Pneumonia: Does B-type Natriuretic Peptide Play a Causative Role? Pediatr Emerg Care. 2018; 34:641-646

https://doi.org/10.1097/PEC.0000000000000814

23. Yap LB, Mukerjee D, Timms PM, Ashrafian H and Coghlan JG. Natriuretic peptides, respiratory disease, and the right heart. Chest. 2004;126:1330-1336.

https://doi.org/10.1378/chest.126.4.1330

24. WrotekA and Jackowska T. Hyponatremia in children hospitalized due to pneumonia. Adv Exp Med Biol. 2013;788:103-108.

https://doi.org/10.1007/978-94-007-6627-3_16

25. Al Shibli A, Abukhater D, Al Kuwaiti N, Bassel M, Al Harbi NM, Al Kaabi A, et al. Hyponatraemia and neurological complications in children admitted with bronchiolitis. Paediatr Int Child Health. 2016;36:175-180.

https://doi.org/10.1080/20469047.2016.1162390

\section{Authors Contribution:}

YT - Concept and design of the study, prepared first draft of manuscript; AK, DB - Interpreted the results, reviewed the literature and manuscript preparation YT, Al, HS - Concept, coordination, review of literature and manuscript preparation; HK, EMÖ, MTP - Statistically analyzed and interpreted, preparation of manuscript and revision of the manuscript.

\section{Work attributed to:}

University of Health Science Okmeydani Training and Research Hospital, Istanbul. Turkey.

Orcid ID:

Dr. Yelda Turkmenoglu - (1) https://orcid.org/0000-0001-7472-8748

Dr. Alper Kacar - (i) https://orcid.org/0000-0001-7577-5386

Dr. Diğdem Bezen - (1) https://orcid.org/0000-0003-3977-5527

Dr. Haticenur Kırar - (10 https://orcid.org/0000-0002-7549-6886

Dr. Ebru Mısırlı Özdemir - (D) https://orcid.org/0000-0002-1243-2527

Dr. Ahmet Irdem - (1) https://orcid.org/0000-0002-2565-5674

Dr. Mey Talip Petmezci - (1) https://orcid.org/0000-0002-6409-3854

Dr. Hasan Dursun - it https://orcid.org/0000-0002-8817-494X

Source of funding: Nil, Conflict of Interest: None declared. 